
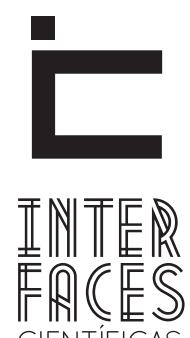

CIENTÍFICAS

DIREITO

\title{
LINHA EDITORIAL E REGRAS DE SUBMISSÃO
}

\author{
EDITORIAL LINE AND SUBMISSION RULES
}

EDITORIAL Y NORMAS DE PRESENTACIÓN DE LA LÍNEA

\section{1 - LINHA EDITORIAL, FOCO E ESCOPO}

A Revista Interfaces Científica - Direito, conta com as linhas editoriais "Direitos Fundamentais Sociais" e "Direitos Fundamentais Individuais e Coletivos" e tem por foco os integrantes da comunidade jurídica e também das ciências sociais e humanas de um modo geral. Seu escopo é oferecer a este público um espaço de discussão de alto nível sobre as questões mais relevantes ligadas a estas áreas. Nossa missão é produzir conhecimento acadêmico-científico de qualidade. Propõe também ser um espaço de interdisciplinaridade com outros segmentos de pesquisa.

\section{2 - PROCESSO DE AVALIAÇÃO PELOS PARES}

A Revista Interfaces Científica - Direito, conta com um grupo de avaliadores de alto nível, procedentes de universidades estrangeiras e de todas as regiões do Brasil, com experiência na área de ciências sociais e humanas, atuação, produção e experiência na área jurídica. 0 processo de seleção en- volve a submissão, a no mínimo dois avaliadores, de trabalhos originais, sem identificação e adequados ao escopo da Revista. A submissão será feita por via eletrônica, terá início com o parecer de um dos componentes do Conselho Editorial, responsável por reconhecer ou não o artigo como dentro do escopo da revista, e será concluído em até quatro semanas. Quando um artigo recebe dois pareceres em sentidos contrários (um deles favorável à publicação e outro desfavorável à publicação), ele é encaminhado para um terceiro parecerista para que seja realizada uma avaliação de minerva. Dessa forma, um artigo que recebeu um parecer desfavorável pode, por fim, ser aprovado após receber um segundo parecer favorável pelo avaliador de minerva. Os artigos serão avaliados de acordo com os seguintes critérios: originalidade do trabalho, clareza quanto aos objetivos propostos, profundidade, atualidade da revisão bibliográfica realizada, adequação da metodologia utilizada, grau em que os objetivos propostos foram 
alcançados, coerência da conclusão com os dados apresentados, forma geral do texto (estrutura de apresentação, clareza da redação, correção gramatical e adequação às normas) e relevância do trabalho para a área.

\section{3 - PERIODICIDADE}

A publicação será quadrimestral, sendo a recepção de originais em fluxo contínuo.

\section{4 - POLÍTICA DE ACESSO LIVRE}

Esta revista oferece acesso livre imediato ao seu conteúdo, seguindo o princípio de que disponibilizar gratuitamente o conhecimento científico ao público proporciona maior democratização mundial do conhecimento.

\section{5 - DIRETRIZES PARA AUTORES}

As normas de submissão são requisitos básicos para aceitação de trabalhos a serem publicados em qualquer uma das revistas desta plataforma. Os autores devem observar requisitos de estrutura, formatação, citações e referências.

Os originais devem estar em português, inglês ou espanhol, devem ser inéditos e destinar-se exclusivamente ao Portal de Periódicos da Sociedade de Educação Tiradentes, não sendo permitida sua apresentação simultânea a outro periódico, tanto no que se refere ao texto, como figuras ou tabelas, quer na íntegra ou parcialmente, excetuando-se resumos ou relatórios preliminares publicados em Anais de Reuniões Científicas.

\section{Submissão de artigos online}

Os artigos devem ser submetidos, exclusivamente de forma eletrônica através do Portal de Periódicos da Sociedade de Educação Tiradentes. Disponível em:

http://periodicos.set.edu.br/index.php

\section{Artigos enviados por e-mail não serão considerados}

Todos os direitos editoriais são reservados para as publicações do Portal de Periódicos SET, nenhuma parte das publicações pode ser reproduzida, estocada por qualquer sistema ou transmitida por quaisquer meios ou formas existentes ou que venham a ser criados, sem prévia permissão por escrito da Comissão Editorial, ou sem constar o crédito de referência, de acordo com as leis de direitos autorais vigentes no Brasil.

\section{Ética na pesquisa}

Nas pesquisas envolvendo seres humanos, os autores deverão enviar uma cópia de aprovação emitida pelo Comitê de Ética, reconhecido pela Comissão Nacional de Ética em Pesquisa (CONEP), segundo as normas da Resolução do Conselho Nacional de Saúde - CNS 196/96 ou órgão equivalente no país de origem da pesquisa.

\section{Categorias de manuscritos aceitos:}

Artigo original: trabalho de pesquisa com resultados inéditos e que agreguem valor à publicação. Limitado com no mínimo oito páginas e no máximo 15 páginas. Sua estrutura deve conter:

- Introdução: deve ser breve, definir o problema estudado, destacando a sua importância e as lacunas do conhecimento. NBR 6022:2003

- Método: os métodos empregados, a população estudada, a fonte de dados e os critérios de seleção devem ser descritos de forma objetiva e completa. Inserir o número do protocolo de aprovação do Comitê de Ética em Pesquisa e informar que a pesquisa foi conduzida de acordo com os padrões éticos exigidos.

- Resultados: devem ser apresentados de forma clara e objetiva, descrevendo somente os dados encontrados sem interpretações ou comentários, podendo para maior facilidade de compreensão serem acompanhados por tabelas, quadros e figuras. 0 texto deve complementar e não repetir o que está descrito nas ilustrações.

- Discussão: deve restringir-se aos dados obtidos e aos resultados alcançados, enfatizando os novos e importantes aspectos observados no estudo e discutindo as concordâncias e divergências com outras pesquisas já publicadas. 
- Conclusão: deve corresponder aos objetivos ou hipóteses do estudo, fundamentada nos resultados e discussão, coerente com o título, proposição e método.

- Estudo teórico: análise de estudos teóricos, levando ao questionamento de modelos existentes e à elaboração de hipóteses para futuras pesquisas. Limitado a 15 páginas. Cerca de no máximo 36.000 caracteres com espaço.

\section{Forma e preparação de manuscritos}

Os textos enviados em Língua Portuguesa devem estar escritos conforme o Novo Acordo Ortográfico que passou a vigorar em janeiro de 2009. Tamanho A4, com espaço entrelinhas de $1,5 \mathrm{~cm}$, fonte arial, tamanho 12, e as margens: superior e esquerda $3 \mathrm{~cm}$, margens inferior e direita $2 \mathrm{~cm}$.

Página de identificação: deve conter o título do artigo (máximo de 16 palavras) em português, inglês e espanhol, sem abreviaturas e siglas; nome(s) do(s) autor(es), indicando no rodapé da página a função que exerce $(m)$, a instituição a qual pertence $(m)$, títulos e formação profissional, endereço (cidade, estado e país) para troca de correspondência, incluindo e-mail, de preferência institucional, e telefone. Se o artigo for baseado em tese ou dissertação, indicar o título, o nome da instituição e o ano de defesa.

- Citações NBR 10520:2002 - Sistema autor-data - Neste sistema, a indicação da fonte é feita: a) pelo sobrenome de cada autor ou pelo nome de cada entidade responsável até o primeiro sinal de pontuação, seguido(s) da data de publicação do documento e da(s) página(s) da citação, no caso de citação direta, separados por vírgula e entre parênteses;

- Notas de rodapé - deverão ser evitadas e usadas quando extremamente necessárias. Deverão ser indicados por ordem numérica;

- Depoimentos - frases ou parágrafos ditos pelos sujeitos da pesquisa deverão seguir a mesma regra de citações, quanto a aspas e recuo $(4 \mathrm{~cm}$ além das margens), utilizando o sistema autor data;
- Ilustrações - as tabelas, quadros e figuras devem ter um título breve, serem numeradas consecutivamente com algarismos arábicos na ordem em que forem inseridas no texto, sendo limitadas a cinco no conjunto. Exceto tabelas e quadros, todas as ilustrações devem ser designadas como figuras. As tabelas devem incluir apenas os dados imprescindíveis, evitando-se tabelas muito longas, não utilizar traços internos horizontais ou verticais, estas devem seguir os procedimentos do IBGE. As notas explicativas devem ser colocadas no rodapé das tabelas e não no cabeçalho ou título. Quando a tabela ou figura forem extraídas de outro trabaIho, a fonte original deve ser mencionada. Devem estar em resolução de $300 \mathrm{dpi}$, colorida, em formato digital (jpg) e deverão ser postadas no portal da revista como documento complementar. Ver: estrutura e normas;

- Tabelas - em resolução superior a 300 dpi, colorida, em formato digital (jpg) e deverão ser postadas no portal da revista como documento complementar. Ver: estrutura e normas;

- Figuras (fotos, desenhos, gráficos etc) - serão publicadas sem identificação dos sujeitos, a menos que acompanhadas de permissão por escrito de divulgação para fins científicos. As figuras não devem repetir dados já descritos em tabelas. Devem estar em resolução de 300 dpi, colorida, em formato digital (jpg) e deverão ser postadas no portal da revista como documento complementar. Ver: estrutura e normas;

- Apêndices e anexos - devem ser evitados.

- Agradecimentos - contribuições de pessoas que prestaram colaboração intelectual ao trabalho como assessoria científica, revisão crítica da pesquisa, coleta de dados entre outras, mas que não preencham os requisitos para participar de autoria, devem constar dos "Agradecimentos", no final do trabalho, desde que haja permissão expressa dos nomeados. Também poderão ser mencionadas, as instituições que deram apoio, assistência técnica e outros auxílios.

- Errata: após a publicação do artigo, se os autores identificarem a necessidade de errada, deverão enviá-la ao Editor da revista, por email. 
Resumo: deve ser apresentado em português (resumo), inglês (abstract) e espanhol (resumen), com até 250 palavras, explicitando o objetivo da pesquisa, método, resultados e conclusões, com base na Norma NBR 6028.

Palavras-chave: devem ser indicados de três a seis palavras-chave que permitam identificar o assunto do trabalho, acompanhando o idioma dos resumos: português (Descritores), inglês (Descriptors), espanhol (Descriptores) e Francês (Mots- Clés), extraídos dos vocabulários adotados. No caso dos Descritores em Ciências da Saúde, utilizar o DeCS (Descritores em Ciências da Saúde), elaborado pela BIREME e/ou (MeSH) Medical Subject Headings, elaborado pela NLM (National Library of Medicine).

Referências: As referências dos documentos impressos e eletrônicos devem ser normalizadas de acordo com as Normas da ABNT 6023/2002 e para área de saúde. Recomenda-se que o número de referências não ultrapasse a 20 . Sugere-se incluir aquelas estritamente pertinentes à problemática abordada e evitar a inclusão de número excessivo de referências numa mesma citação. A exatidão das referências é de responsabilidade dos autores.

\section{NORMAS ABNT}

ABNT. NBR 6022: informação e documentação artigo em publicação periódica científica impressa apresentação. Rio de Janeiro, 2003.

ABNT. NBR 6023: informação e documentação (referências - Elaboração)

ABNT. NBR 6028: resumos. Rio de Janeiro, 1990.

ABNT. NBR 14724: informação e documentação trabalhos acadêmicos - apresentação. Rio de Janeiro, 2002.(informações pré-textuais, informações textuais e informações pós-textuais)

ABNT. NBR 10520: informações e documentação - citações em documentos - apresentação. Rio de Janeiro, 2002.

\section{6 - CONDIÇÕES PARA SUBMISSÃO}

Como parte do processo de submissão, os autores são obrigados a verificar a conformidade da submis- são em relação a todos os itens listados a seguir. As submissões que não estiverem de acordo com as normas serão devolvidas aos autores.

1. A contribuição é original e inédita, e não está sendo avaliada para publicação por outra revista; caso contrário, deve-se justificar em "Comentários ao editor".

2. 0 arquivo da submissão está em formato Microsoft Word.

3. URLs para as referências foram informadas quando possível.

4. Os textos enviados em Língua Portuguesa devem estar escritos conforme o Novo Acordo Ortográfico que passou a vigorar em janeiro de 2009. Tamanho A4, com espaço entrelinhas de $1,5 \mathrm{~cm}$, fonte arial, tamanho 12, e as margens: superior e esquerda $3 \mathrm{~cm}$, margens inferior e direita $2 \mathrm{~cm}$.

5. 0 texto segue os padrões de estilo e requisitos bibliográficos descritos em Diretrizes para Autores, na página Sobre a Revista.

6. Em caso de submissão a uma seção com avaliação pelos pares (ex.: artigos), as instruções disponíveis em Assegurando a avaliação pelos pares cega foram seguidas.

\section{7 - DECLARAÇÃO DE DIREITO AUTORAL}

A Revista Interfaces Científicas - Direito, oferece acesso livre e imediato ao seu conteúdo, seguindo o princípio de que disponibilizar gratuitamente o conhecimento científico contribui para a democratização do saber. Assim, ao submeter os originais os autores cedem os direitos de publicação para a Revista. 0 autor(a) reconhece esta como detentor(a) do direito autoral e ele autoriza seu livre uso pelos leitores, podendo ser, além de lido, baixado, copiado, distribuído e impresso, desde quando citada a fonte.

\section{8 - POLÍTICA DE PRIVACIDADE}

Os nomes e endereços informados nesta revista serão usados exclusivamente para os serviços prestados por esta publicação, não sendo disponibilizados para outras finalidades ou a terceiros. 